\title{
The electrochemical reduction of a cadmium cryptate on a mercury electrode in acetonitrile
}

\author{
Jadwiga Stroka \\ Department of Chemistry, University of Warsaw, 02093 Warszawa (Poland) \\ Brian G. Cox \\ Department of Chemistry, University of Stirling, Stirling FK9 4LA (Great Britain) \\ Hermann Schneider \\ Max-Planck-Institut für biophysikalische Chemie, D-3400 Göttingen (F.R.G.) \\ (Received 6 June 1988; in revised form 2 February 1989)
}

\begin{abstract}
The reduction of the $\mathrm{Cd}(2,2,2)^{2+}$ complex has been studied in acetonitrile using polarography, chronocoulometry, and cyclic voltammetry. The corresponding kinetic parametcrs have been calculated and are compared with those obtained for the solvated cadmium cation in the same solvent. The study of the electrochemical reduction mechanism showed that the final stable products are the free ligand $(2,2,2)$ and cadmium-amalgam. The stability constant of the cadmium cryptate in acetonitrile has been estimated as $\log K_{\mathrm{s}}=17.3$ from the electrochemical measurements.
\end{abstract}

\section{INTRODUCTION}

In 1968 Dietrich et al. [1,2] first synthesised cryptands, bicyclic diaza polyethers, which form very stable complexes (cryptates) with alkali and alkaline earth cations in water and organic solvents. Structural studies revealed that the cryptates of alkali and alkaline earth cations generally exhibit $1 / 1$ stoichiometry, with the cations normally being located within the intramolecular cavity of the cryptands. However. much less is known about the structures and thermodynamic properties of transition metal cation complexes of cryptands. It was found that the transition metal cations form mostly mononuclear $1 / 1$ complexes, but in some cases the formation of binuclear $(2 / 1)$ complexes is also possible [3].

The electrochemical behaviour of macrocyclic complexes of alkali [4-6] and alkaline earth [7] cations in propylene carbonate (PC) has been reported recently. It was found that the $\mathrm{K}^{+}$cation forms stable inclusion complexes [3] with cryptands 
$(3,2,2),(2,2,2)$ and $(2,2,1)$ in $\mathrm{PC}$ solutions. The electrochemical reduction of these complexes is highly irreversible and occurs at potentials quite negative compared to the reduction of solvated $\mathrm{K}^{+}$. The final stable products of the reduction have been identified as a $\mathrm{K}$-amalgam and free ligand. For the stable cryptand inclusive complexes the EC mechanism was proposed, in which the rate determining step is the charge transfer $[3,6]$. The reduction mechanism of the $\mathrm{Na}(2,2,2)^{+}$and $\mathrm{Li}(2,2,2)^{+}$ cryptates [6] is probably the same because the electrochemical behaviour of these cryptates is similar to that of the $\mathrm{K}(\mathrm{Cry})^{+}$inclusion complexes.

The electrochemical reduction of the cryptates $\mathrm{M}(2,2,1)^{2+}(\mathrm{M}=\mathrm{Fe}, \mathrm{Co}, \mathrm{Ni})$ has also been studied on the mercury electrode in PC solutions [8]. In this case the reduction on the mercury electrode is a slow two-electron process, and the electrochemical step precedes the chemical decomplexation. For each of the complexes the free ligand $(2,2,1)$ is one of the final reduction products, and the reduction mechanism was also interpreted as an EC mechanism [8].

It is noteworthy, that the reduction of the $\mathrm{Tl}(2,2,2)^{+}$complexes on the mercury electrode in PC solutions [9] leads, according to the authors, to the product $\mathrm{Tl}^{11}(2,2,2)$ which is subsequently oxidised in the anodic process. The electrochemically estimated stability constant of $\mathrm{Tl}(2,2,2)^{+}$complexes is about three orders of magnitude lower than that ohtained from potentiometric measurements [10].

The present study is devoted to the electrochemical reduction of the cadmium cryptate, $\mathrm{Cd}(2,2,2)^{2+}$, on a mercury electrode in acetonitrile (AN). The aim of the research was to determine the mechanism and the kinetic parameters of the electrode process.

\section{EXPERIMENTAL}

All measurements have been carried out in acetonitrile (Merck, spectroscopically pure). The supporting electrolyte was $0.1 M$ tetraethylammonium perchlorate (TEAP) (Fluka). TEAP was recrystallised and dried for $48 \mathrm{~h}$ at $50^{\circ} \mathrm{C}$ under reduced pressurc before use. The ligand, cryptand $(2,2,2)$ (Merck), was used without further purification. $\mathrm{Cd}\left(\mathrm{ClO}_{4}\right)_{2}$ (Ventron) was dried for $24 \mathrm{~h}$ at $80^{\circ} \mathrm{C}$ under reduced pressure.

Solutions used in the measurements were normally prepared by consecutive dilution of stock solutions. However, in the case of highly concentrated ligand solutions, the appropriate quantity of ligand was weighed directly. A hanging mercury drop electrode (HMDE) and/or a dropping mercury electrode (DME) were used as indicator electrodes in a three-electrode measuring system. A Pt gauze constituted the counter clectrode. All potentials were measured against an aqueous calomel electrode saturated with sodium chloride, and the reference electrode was separated from the measuring cell by a salt bridge.

All measurements were carried out at $25 \pm 0.1^{\circ} \mathrm{C}$ using a water-jacketed cell. Argon, used for deoxygenation of the solutions, was first passed through traps filled consecutively with $\mathrm{H}_{2} \mathrm{SO}_{4}$ and the solution under study. The $\mathrm{Cd}^{2+}$ concentration was $5 \times 10^{-4} \mathrm{M}$ in all solutions. 
The electrochemical methods used in this work were: (i) normal pulse polarography, (ii) voltammetry, and (iii) single potential step chronocoulometry. Pulse experiments were carried out using equipment based on a design developed in Gierst's laboratory. For techniques (i) and (ii), a linear sweep generator (type EG-20 ELPAN) connected with a potentiostat (type 50-05 ELPAN) and an X-Y recorder (type 30A Yokogawa) were used. Voltammetric curves at higher scan rates were recorded on the screen of an oscilloscope.

\section{RESULTS}

Electrochemical behaviour of the $C d(2,2,2)^{2+}$ complex in acetonitrile

The polarographic and cyclic voltammetric curves were recorded over the potential range 0 to $-1.2 \mathrm{~V}$ vs. $\mathrm{SCE}$ in $\mathrm{AN}$ solutions containing $5 \times 10^{-4} M \mathrm{Cd}\left(\mathrm{ClO}_{4}\right)_{2}$ and $0.1 M$ TEAP. Experiments were performed under the same conditions on $\mathrm{Cd}^{2+}$ solutions to which successive aliquots of a ligand had been added, with ligand concentrations varying between 0 and $5.36 \times 10^{-2} \mathrm{M}$.

\section{Polarographic investigations}

It is necessary here to consider two different experimental situations, corresponding to concentration ratios of $(2,2,2)$ to $\mathrm{Cd}^{2+}\left((2,2,2) / \mathrm{Cd}^{2+}\right)$ greater or less than one, respectively. For $(2,2,2) / \mathrm{Cd}^{2+}<1$, two distinct reduction waves, whose halfwave potentials were separated from each other by about $0.5 \mathrm{~V}$ (see Fig. 1, curve 2), were observed. The first wave $\left(E_{1 / 2}=-0.3 \mathrm{~V}\right)$ corresponds to the reduction of solvated cadmium cations, whereas the second, more negative wave $\left(E_{1 / 2}=-0.820\right.$ V) corresponds to the reduction of $\operatorname{Cd}(2,2,2)^{2+}$. The limiting currents of the two

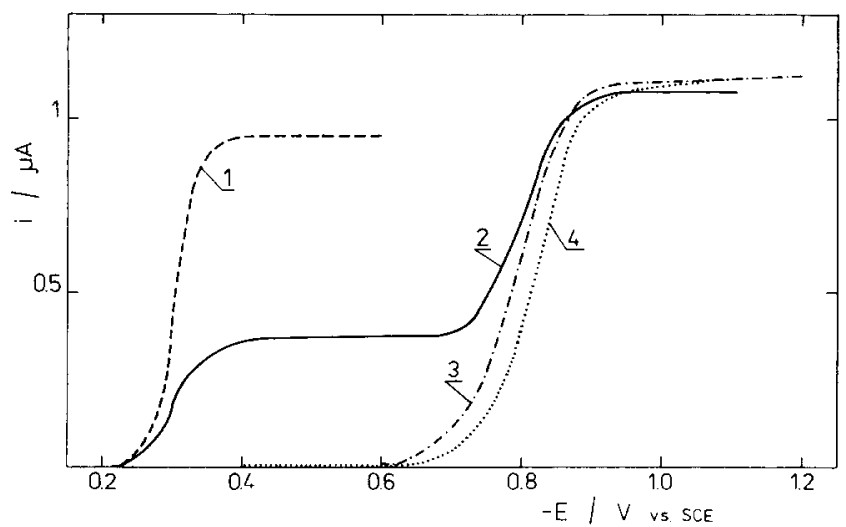

Fig. 1. Polarographic curves in AN $+0.1 M$ TEAP $+5 \times 10^{-4} M \mathrm{Cd}^{2+}$ at ratios of concentrations of ligand (2,2,2) in $\mathrm{CA}^{2+}$ equal to 0 (curve 1); 0.6 (curve )); 1 (curve 3); 100 (curve 4). Capillary parameter $m=0.287 \mathrm{mg} \mathrm{s}^{-1}$. 


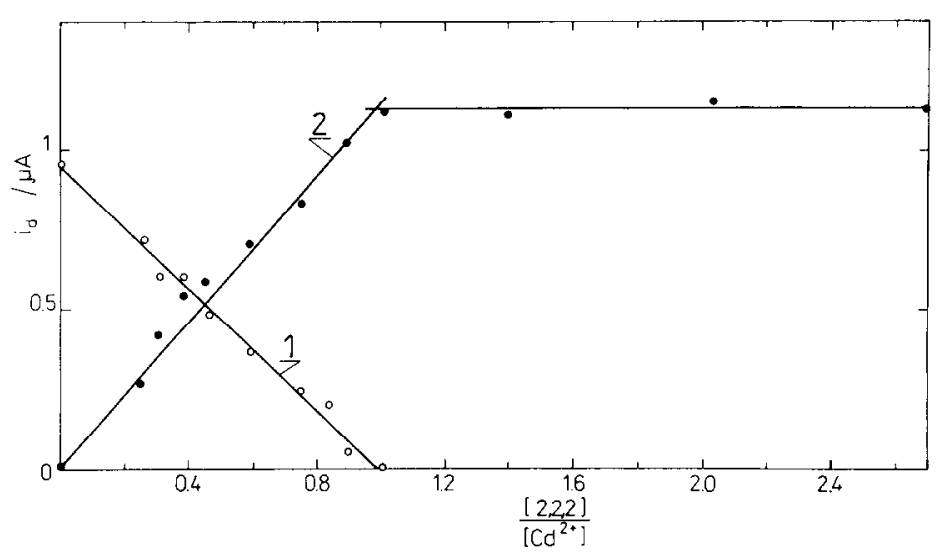

Fig. 2. Polarographic limiting currents in AN $+0.1 M$ TEAP $+5 \times 10^{-4} M \mathrm{Cd}^{2+}$ as a function of the ratio of concentrations of $(2,2,2)$ to $\mathrm{Cd}^{2+}$. Curve 1 for $\mathrm{Cd}^{2+}$ ions, curve 2 for $\mathrm{Cd}(2,2,2)^{2+}$ cryptate; $m=0.287 \mathrm{mg} \mathrm{s}^{-1}$.

waves are proportional to the concentrations of $\mathrm{Cd}^{2+}$ and $\mathrm{Cd}(2,2,2)^{2+}$, respectively. Addition of the ligand $(2,2,2)$ to a solution in which $[(2,2,2)] /\left[\mathrm{Cd}^{2+}\right]<1$ leads to a successive decrease of the $\mathrm{Cd}^{2+}$ reduction wave towards zero as the ratio of the concentrations of $(2,2,2)$ to $\mathrm{Cd}^{2+}$ approaches unity: beyond this only the reduction wave of $\mathrm{Cd}(2,2,2)^{2+}$ is observed (Fig. 2). The polarographic results suggest that the stoichiometry of the complex investigated is $1 / 1$.

The half-wave potential of the complex in a solution with a large excess of the ligand $\left([(2,2,2)] /\left[\mathrm{Cd}^{2+}\right]=100\right)$ is about $20 \mathrm{mV}$ more negative than in a solution containing equal concentrations of ligand and $\mathrm{Cd}^{2+}$. Logarithmic analysis of the reduction wave of $\mathrm{Cd}(2,2,2)^{2+}$ shows that the electrochemical reduction of the complex is irreversible; the slope $\log \left\{i /\left(i_{\mathrm{d}}-1\right)\right\} / E$ equals $0.075 \pm 0.005 \mathrm{~V}$.

In order to investigate the nature of the transport of $\mathrm{Cd}^{2+}$ to the mercury electrode, the polarographic current was measured as a function of the $\mathrm{Cd}(2,2,2)^{2+}$ concentration in the range $10^{-4}$ to $10^{-3} \mathrm{M}$. The plot of $i_{\mathrm{d}}$ vs. $\left[\mathrm{Cd}(2,2,2)^{2+}\right]$ (Fig. 3) is linear and passes through the origin; this indicates that the reduction process is not preceded by a chemical reaction, and the reactant is not adsorbed on the mercury electrode. This is confirmed additionally by values of the diffusion coefficients of $\mathrm{Cd}^{2}$ and $\mathrm{Cd}(2,2,2)^{2+}$ calculated from the limiting currents which were found to be equal to $6.2 \times 10^{-6}$ and $(8.2 \pm 0.5) \times 10^{-6} \mathrm{~cm}^{2} \mathrm{~s}^{-1}$, respectively, being very similar to diffusion coefficients of other reactants of similar charge and size. The diffusion coefficient of the complex was independent of ligand concentration in the solutions investigated.

\section{Cyclic voltammetric measurements}

Cyclic voltammetric measurements were carried out in order to determine the mechanism of the electrode process. The potential scan rate was varied between 


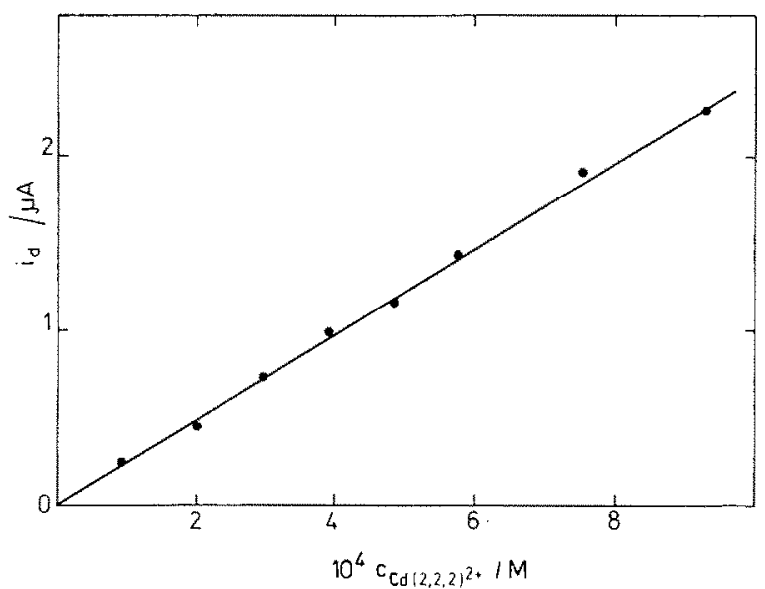

Fig. 3. Polarographic limiting currents in $\mathrm{AN}+0.1 M$ TEAP as a function of $\mathrm{Cd}(2,2,2)^{2+}$ cryptate concentration; $m=0.340 \mathrm{mg} \mathrm{s}^{-1}$.

$10^{-2}$ and $20 \mathrm{~V} \mathrm{~s}^{-1}$ and the results are shown in Fig. 4. In solutions with $[(2,2,2)] /\left[\mathrm{Cd}^{2+}\right]<1$, two cathodic peaks were observed (Fig. 4, curve 2). The first peak corresponds to the reduction of uncomplexed $\mathrm{Cd}^{2+}$ ions, and the second cathodic peak corresponds to the reduction of the $\mathrm{Cd}(2,2,2)^{2+}$ cryptate. With an

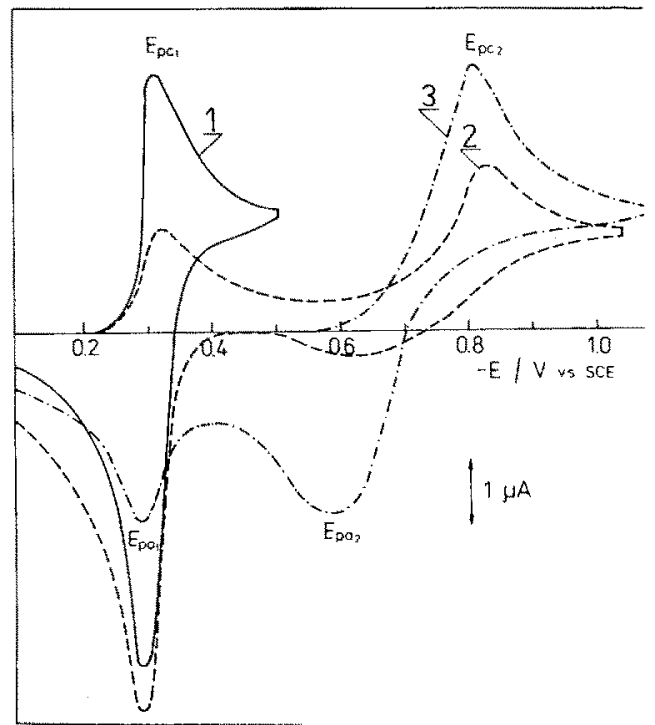

Fig. 4. Cyclic voltammetry in AN+0.1 $M$ TF.AP for different ratios of concentrations of $(2,2,2)$ to $\mathrm{Cd}^{2+}=0$ (curve 1 ); 0.6 (curve 2 ); 1 (curve 3 ). $\mathrm{Cd}^{2+}=5 \times 10^{-4} \mathrm{M}$. Scan rate $v=2 \times 10^{-2} \mathrm{~V} \mathrm{~s}^{-1}$. 


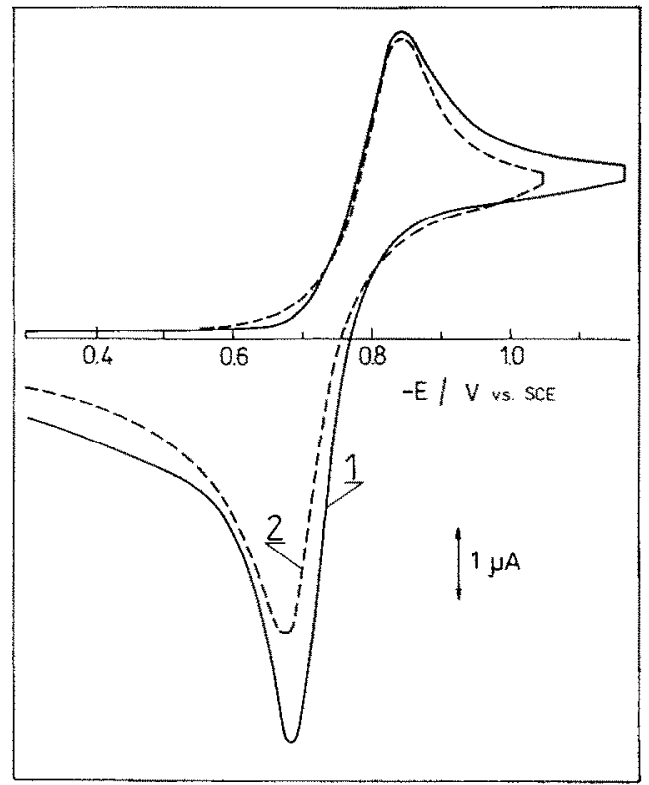

Fig. 5. Cyclic voltammetry of $\mathrm{Cd}(2,2,2)^{2+}$ in AN solution containing $0.1 M \mathrm{TEAP}, 5 \times 10^{-4} M \mathrm{Cd}^{2+}$ and $3.1 \times 10^{-2} M(2,2,2)$ down to $-1.17 \mathrm{~V}$ (curve 1) and $-1.05 \mathrm{~V}$ (curve 2 ); $v=2 \times 10^{-2} \mathrm{~V} \mathrm{~s}^{-1}$.

excess of ligand $\left([(2,2,2)] /\left[\mathrm{Cd}^{2+}\right]=1\right.$ to 100$)$, only one cathodic peak (see Figs. 4 and 5), characteristic of the cryptate reduction, was observed.

The anodic parts of the cyclic voltammograms are of particular interest. In solutions where the ligand concentrations were lower than those of $\mathrm{Cd}^{2+}$, two anodic peaks were observed. The first peak, at potential $E_{\mathrm{pal}}$, corresponds to the oxidation of the cadmium amalgam to uncomplexed $\mathrm{Cd}^{2+}$ ions, and the second, at potential $E_{\mathrm{pa} 2}$, probably corresponds to the oxidation of the cadmium amalgam to the $\mathrm{Cd}(2,2,2)^{2+}$ complex. In solutions containing a large excess of ligand $\left([(2,2,2)] /\left[\mathrm{Cd}^{2+}\right] \geqslant 5\right.$ to 100$)$, only one peak, at a potential close to $E_{\mathrm{pa} 2}$, was observed in the anodic part of the voltammogram. Polarization of the electrode to more negative potentials leads to an increase in the height of the anodic peak (Fig. 5 ), and a ratio of anodic to cathodic peak current which is larger than 1 . This can be explained by the fact that in reduction of the $\mathrm{Cd}(2,2,2)^{2+}$ on the mercury electrode, Cd-amalgam is formed and $(2,2,2)$ is released.

From the voltammetric results presented above we conclude that the oxidation mechanism at the mercury electrode can be written as follows:

$\mathrm{Cd}(\mathrm{Hg})-2 e^{-}+(2,2,2) \rightarrow \mathrm{Cd}(2,2,2)^{2+}$

Cyclic voltammograms were also recorded in solutions containing only a small excess of ligand $\left([(2,2,2)] /\left[\mathrm{Cd}^{2+}\right] \simeq 1\right.$ to 5$)$. When a single potential cycle from 0 to $-1.1 \mathrm{~V}$ was recorded (Fig. 6, curve 1), one anodic and one cathodic peak were 


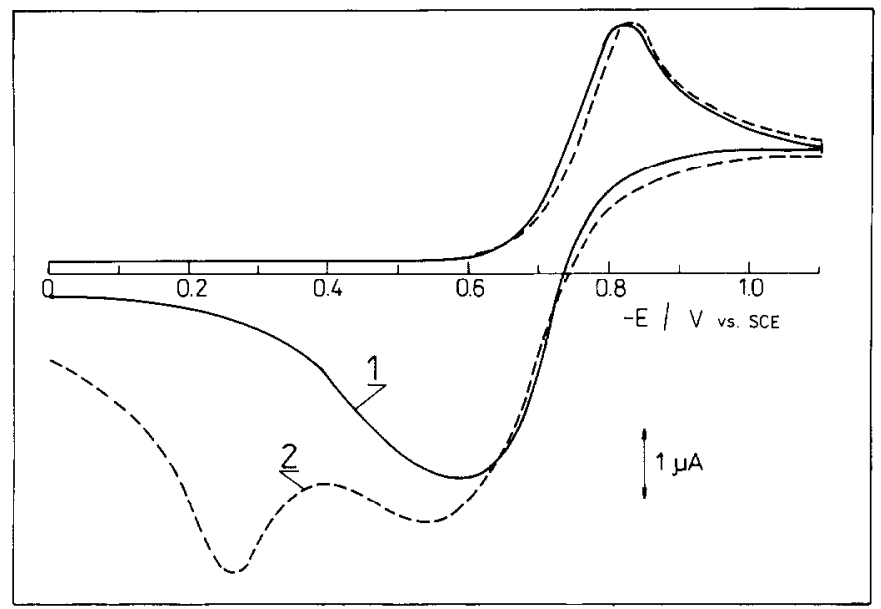

Fig. 6. Cyclic voltammetry of $\mathrm{Cd}(2,2,2)^{2+}$ cryptate in AN solution containing $0.1 \mathrm{M}$ TEAP, $5 \times 10^{-4} \mathrm{M}$ $\mathrm{Cd}^{2+}$ and $1.40 \times 10^{-3} M(2,2,2)$ (curve 1 ). Voltammogram after $60 \mathrm{~s}$ waiting at $-1.1 \mathrm{~V}$ (curve 2); $v=2 \times 10^{-2} \mathrm{~V} \mathrm{~s}^{-1}$.

observed. However, if the experiment was repeated, but with the potential held beforehand at $-1.1 \mathrm{~V}$ for $60 \mathrm{~s}$, for example, an additional anodic peak was observed (Fig. 6, curve 2). The new, more positive peak can be explained by the oxidation of $\mathrm{Cd}(\mathrm{Hg})$ to $\mathrm{Cd}^{2+}$. The amplitude of this peak increases as the polarization time at the potential of -1.1 . $\mathrm{V}$ increases. The above observations are consistent with the fact that during the reduction of $\mathrm{Cd}(2,2,2)^{2+}, \mathrm{Cd}(\mathrm{Hg})$ is formed and $(2,2,2)$ diffuses away from the surface layer into the bulk solution. This also explains the anodic oxidation of $\mathrm{Cd}(\mathrm{Hg})$ which was previously observed at lower reactant concentration. The observed anodic peak at the potential $E_{\mathrm{pa} 2}$ in this case was small (see Fig. 4, curve 2) because the ligand liberated during the cathodic process, and required for reaction (1), is removed by complexation with $\mathrm{Cd}^{2+}$ ions, which are present either in the bulk or in the surface layer.

Finally, the stability constant of the $\mathrm{Cd}(2,2,2)^{2+}$ complex was calculated from the formal potentials taken from the cyclic voltammetric curves. The voltammograms were recorded with a potential scan rate equal to $10^{-2} \mathrm{~V} \mathrm{~s}^{-1}$ in solutions containing respectively uncomplexed $\mathrm{Cd}^{2+}$ and an excess of ligand $\left([(2,2,2)] /\left[\mathrm{Cd}^{2+}\right]=10\right.$ to 100). The formal potentials were calculated using the modified Randles equation [8] because of the irreversibility of the process investigated. The formal potentials were also estimated from the intercept of the Tafel plots calculated from the chronocoulometric curves and were found to be in good agreement $( \pm 5 \mathrm{mV})$ with those obtained from cyclic voltammetry. The formal potentials are shown as a function of the free ligand concentration in Fig. 7: the slope of the plot $(30 \pm 1 \mathrm{mV})$ confirms a $1 / 1$ stoichiometry of the cryptate. 


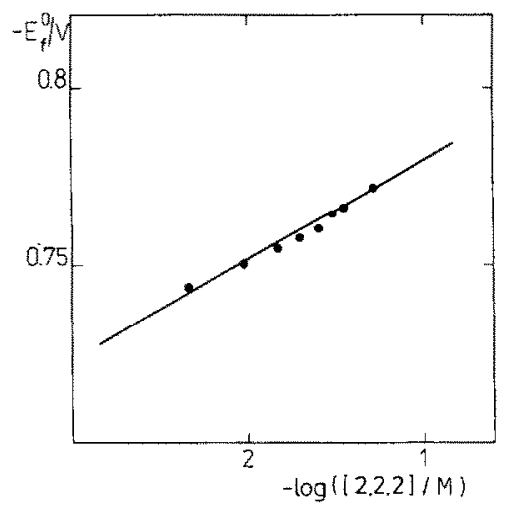

Fig. 7. Formal potential of the $\mathrm{Cd}(2,2,2)^{2+} / \mathrm{Cd}(\mathrm{Hg})$ system in $\mathrm{AN}+0.1 M \mathrm{TEAP}+5 \times 10^{-4} M \mathrm{Cd}^{2+}$ as a function of the free ligand concentration.

The stability constant was calculated using eqn. (2), in which

$$
\begin{aligned}
\frac{R T}{n F} \ln \frac{\left[\mathrm{Cd}(2,2,2)^{2+}\right]}{\left[\mathrm{Cd}^{2+}\right]}= & \frac{R T}{n F} \ln \left(K_{\mathrm{s}}(2,2,2)\right) \\
= & E_{\mathrm{f}}^{\circ}\left(\mathrm{Cd}(2,2,2)^{2+} / \mathrm{Cd}(\mathrm{Hg})\right)-E_{\mathrm{f}}^{\circ}\left(\mathrm{Cd}^{2+} / \mathrm{Cd}(\mathrm{Hg})\right) \\
& -\frac{R T}{2 n F} \ln D_{\mathrm{Cd}^{2+}} / D_{\mathrm{Cd}(2,2,2)^{2+}}
\end{aligned}
$$

$E_{\mathrm{f}}^{\circ}\left(\mathrm{Cd}(2,2,2)^{2+} / \mathrm{Cd}(\mathrm{Hg})\right)$ and $E_{\mathrm{f}}^{\circ}\left(\mathrm{Cd}^{2+} / \mathrm{Cd}(\mathrm{Hg})\right)$ denote the formal potentials of the $\mathrm{Cd}(2,2,2)^{2+} / \mathrm{Cd}(\mathrm{Hg})$ and $\mathrm{Cd}^{2+} / \mathrm{Cd}(\mathrm{Hg})$ systems, respectively, and $K_{s}$ is the stability constant of $\mathrm{Cd}(2,2,2)^{2+}$. The logarithm (base 10) of the stability constant $K_{s}$ of $\mathrm{Cd}(2,2,2)^{2+}$ in AN containing $0.1 \mathrm{~mol} \mathrm{dm}^{-3}$ TEAP was found in this way to be equal to $17.3 \pm 0.2$ (Fig. 8).

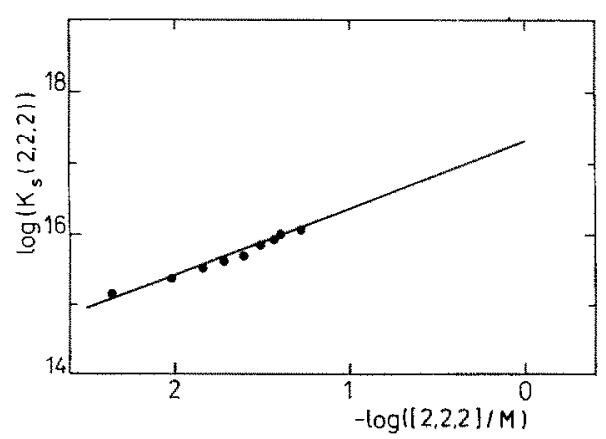

Fig. 8. Fxtrapolation of the product of stability constant and free ligand concentration to the zero value of logarithm of the ligand concentration. Experimental solution; AN $+0.1 M \mathrm{TEAP}+5 \times 10^{-4} M \mathrm{Cd}^{2+}$. 


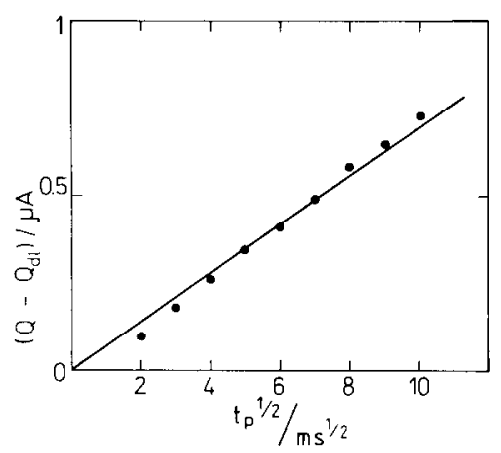

Fig. 9. Limiting cathodic charge as a function of the pulse times in AN $+0.1 M$ TEAP $+5 \times 10^{-4} M$ $\mathrm{Cd}^{2+}$ when $\mathrm{Cd}(2,2,2)^{2+}$ was equal to 9.6. $Q_{\mathrm{dl}}$ is the charge of the double layer.

\section{Kinetic parameters for the $C d(2,2,2)^{2+} / C d(H g)$ system in acetonitrile}

Kinetic parameters were determined using single potential chronocoulometry. This method allows the observation of both the cathodic and anodic processes. The cathodic and anodic chronocoulometric curves were recorded in solutions containing the $\mathrm{Cd}(2,2,2)^{2+}$ complex with varying excesses of ligand $\left([(2,2,2)] /\left[\mathrm{Cd}^{2+}\right]=10\right.$ to 90). Anodic chronocoulometric curves were measured with current integration times of $64,49,36,25$, and $4 \mathrm{~ms}$, and cathodic curves with integration times varying from 100 to $4 \mathrm{~ms}$. The cathodic process was found to be diffusion limited, as the plot of limiting charge vs. the square root of integration time is linear and passes through the origin (Fig. 9).

The chronocoulometric curves were analysed using the Randles method [11]. The standard rate constants were calculated from the intercepts of the anodic and

TABLE 1

Kinetic parameters for the $\mathrm{Cd}(2,2,2)^{2+} / \mathrm{Cd}(\mathrm{Hg})$ system in AN solutions, containing $0.1 \mathrm{~mol} / \mathrm{dm}^{3} \mathrm{TEAP}$, $\mathrm{Cd}^{2+}$ at $5 \times 10^{-4} \mathrm{~mol} / \mathrm{dm}^{3}$ and various concentrations of ligand $(2,2,2)$

\begin{tabular}{llll}
\hline$c_{\mathrm{L}} / \mathrm{mol} \mathrm{dm}^{-3}$ & $-\log \left(k_{\mathrm{s}} / \mathrm{cm} \mathrm{s}^{-1}\right)$ & $\alpha n$ & $\beta n$ \\
\hline 0 & $0.72^{\mathrm{a}}$ & $0.3^{\mathrm{a}}$ & - \\
$5.9 \times 10^{-4}$ & 3.48 & 0.8 & 0.45 \\
$4.8 \times 10^{-3}$ & 3.30 & 0.81 & 0.45 \\
$9.9 \times 10^{-3}$ & 3.14 & 0.79 & 0.42 \\
$1.53 \times 10^{-2}$ & 3.10 & 0.79 & 0.42 \\
$2.9 \times 10^{-2}$ & 2.96 & 0.82 & 0.37 \\
$2.55 \times 10^{-2}$ & 2.90 & 0.83 & 0.35 \\
$2.55 \times 10^{-2}$ & 2.92 & 0.85 & 0.38 \\
$3.05 \times 10^{-2}$ & 2.93 & 0.85 & 0.40 \\
$4.06 \times 10^{-2}$ & 2.81 & 0.83 & 0.43 \\
$4.56 \times 10^{-2}$ & 2.68 & - & 0.46 \\
\hline
\end{tabular}

${ }^{a}$ Data obtained by Biegler et al. [12] in $0.9 \mathrm{~mol} / \mathrm{dm}^{3} \mathrm{AN}$ in $\mathrm{NaClO}_{4}$ as supporting electrolyte. 

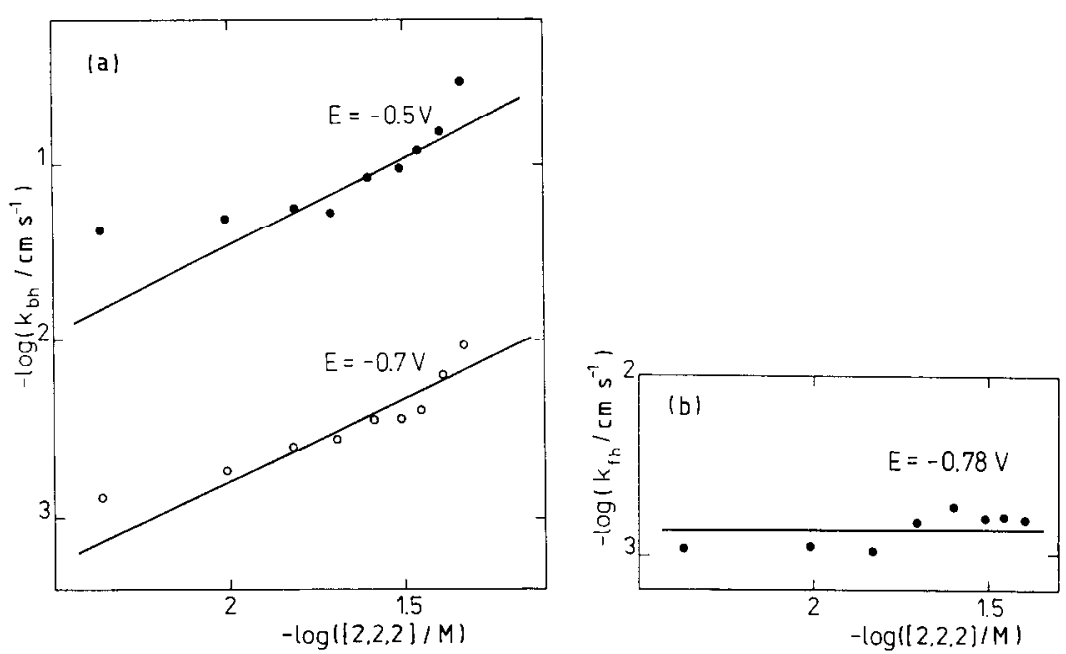

Fig. 10. Dependence of the rate constant of the $\mathrm{Cd}(2,2,2)^{2+} / \mathrm{Cd}(\mathrm{Hg})$ system on the free ligand concentration. (a) Anodic rate constant; (b) cathodic rate constant.

cathodic Tafel curves at the formal potential, and were reproducible to within $\pm 0.07 \mathrm{log}$ units for the integration times used. For solutions with a very large excess of ligand $\left([(2,2,2)] /\left[\mathrm{Cd}^{2+}\right] \simeq 90\right)$ the standard rate constants were calculated only from the anodic Tafel curves, as maxima were observed on the cathodic curves. The cathodic and anodic transfer coefficients were calculated from the slopes of the cathodic and anodic curves, respectively. The reproducibility of the values of $\alpha n$ and $\beta n$ for all of the solutions investigated was within \pm 0.03 .

The kinetic parameters are collected in Table 1 . It can be seen that the standard rate constants increase slightly with increasing ligand $(2,2,2)$ concentration. The apparent cathodic and anodic transfer coefficients are independent of ligand concentration, and have values of $0.82 \pm 0.03$ and $0.42 \pm 0.05$, respectively.

The cathodic $\left(z_{\text {red }}\right)$ and anodic $\left(z_{\mathrm{ox}}\right)$ reaction orders were calculated from the dependence of the logarithm of the cathodic $\left(k_{\mathrm{fh}}\right)$ and anodic $\left(k_{\mathrm{bh}}\right)$ rate constants at constant electrode potential on the logarithm of the free ligand concentration (Figs. 10a and 10b). The cathodic reaction order is close to zero and the anodic one close to 1 . This result confirms that the electrooxidation mechanism can be described by eqn. (1). The data obtained in the polarographic and cyclic voltammetric curves, and the value of $z_{\text {red }}$, lead to the conclusion that the species reduced on the mercury electrode is the $\mathrm{Cd}(2,2,2)^{2+}$ complex, and that the reduction is a two-electron process.

\section{DISCUSSION}

In acetonitrile solutions containing $0.1 M$ TEAP, the cadmium cation forms only a single complex with $(2,2,2)$, with $1 / 1$ stoichiometry, $\mathrm{Cd}(2,2,2)^{2+}$. The complex is 
very stable, with $\log K_{\mathrm{s}}=17.3$. In different solvents, the stability constant increases in the order $\mathrm{H}_{2} \mathrm{O}[3]<\mathrm{MeOH}[3]<\mathrm{AN}$. The Gibbs energy of transfer of the $\mathrm{Cd}(2,2,2)^{2+}$ cryptate from water to AN may be calculated from

$$
\begin{aligned}
\Delta G_{\mathrm{tr}}\left(\mathrm{Cd}(2,2,2)^{2+}\right) & =\Delta G_{\mathrm{tr}}\left(\mathrm{Cd}^{2+}\right)+\Delta G_{\mathrm{tr}}(2,2,2)-R T \ln \left(K_{\mathrm{s}}(\mathrm{AN}) / K_{\mathrm{s}}\left(\mathrm{H}_{2} \mathrm{O}\right)\right) \\
& =15.0 \mathrm{~kJ} \mathrm{~mol}^{-1}
\end{aligned}
$$

This gives a value of $15.0 \mathrm{~kJ} \mathrm{~mol}^{-1}$ using $\Delta G_{\mathrm{tr}}\left(\mathrm{Cd}^{2+}\right)=69.9 \mathrm{~kJ} \mathrm{~mol}^{-1}$ [13], $\Delta G_{\mathrm{tr}}(2,2,2)=4.9 \mathrm{~kJ} \mathrm{~mol}^{-1}[14]$, and the stability constant in water, $\log K_{\mathrm{s}}=6.8$ [15]. It can be seen that the Gibbs energy of transfer of $\mathrm{Cd}(2,2,2)^{2+}$ from water to $\mathrm{AN}$ is much smaller than that of the uncomplexed $\mathrm{Cd}^{2+}$ cation. This suggests that complexation of $\mathrm{Cd}^{2+}$ by the cryptand $(2,2,2)$ leads to a reduction in the solvation energy in both water and acetonitrile and an almost complete screening by the ligand of the metal ion from the surrounding solvent.

The $\mathrm{Cd}(2,2,2)^{2+}$ complex in $\mathrm{AN}$ has the following electrochemical characteristics:

(1) The half-wave potential of the $\mathrm{Cd}(2,2,2)^{2+}$ cryptate is about $0.5 \mathrm{~V}$ more negative than that of the uncomplexed $\mathrm{Cd}^{2+}$ cations.

(2) When the ratio of ligand to cation concentration is less than 1, two well-separated polarographic waves are observed, the heights of which are proportional to the concentrations of $\mathrm{Cd}^{2+}$ and $\mathrm{Cd}(2,2,2)^{2+}$.

(3) When $[(2,2,2)] /\left[\mathrm{Cd}^{2+}\right] \geqslant 1$, only one reduction wave is observed, with an $E_{1 / 2}$ value which is slightly dependent upon the ligand concentration.

(4) The cathodic reduction of the $\mathrm{Cd}(2,2,2)^{2+}$ complex is diffusion limited.

The oxidation mechanism of the Cd-amalgam in the presence of the ligand is described by eqn. (1).

The final stable products of the electroreduction of $\mathrm{Cd}(2,2,2)^{2+}$ have been identified as the Cd-amalgam and the free ligand $(2,2,2)$. We believe that the cathodic reduction occurs according to the concerted electron transfer dissociation step mechanism. Most probably the kinetically determining step is the charge transfer and the dissociation step is fast, because the cathodic rate constants obtained were independent of the current integration times used.

The electrochemical behaviour observed here is very similar to that obtained for the inclusive alkali metal cryptates in propylene carbonate (PC) [4]. We think that in both cases the reduction mechanism is the concerted electron transfer dissociation step mechanism. The standard rate constant for the $\mathrm{Cd}(2,2,2)^{2+}$ complex is about two orders of magnitude lower than that for the electroreduction of uncomplexed $\mathrm{Cd}^{2+}$ ions in AN (Table 1). In the $\mathrm{Cd}(2,2,2)^{2+}$ complex, interaction between the cadmium ion and the electrode is probably prevented by the strong interaction between the ligand and the $\mathrm{Cd}^{2+}$, and also by the very slow dissociation rate constant for the complex. The formation and dissociation rate constants for $\mathrm{Cd}(2,2,2)^{2+}$ have been measured in methanol [16] with values $k_{\mathrm{f}}=4.9 \times 10^{7} \mathrm{M}^{-1}$ $\mathrm{s}^{-1}$ and $k_{\mathrm{d}}=1.9 \times 10^{-3} \mathrm{~s}^{-1}$. If the formation rate constant for the complex in AN is comparable to that in methanol, then, in view of the high thermodynamic stability 
of $\mathrm{Cd}(2,2,2)^{2+}$ in $\mathrm{AN}$, it is clear that the dissociation rate constant is very low indeed in AN.

However, since the very stable $\mathrm{Cd}(2,2,2)^{2+}$ complex is reduced on the mercury electrode, it is possible that in the activated state the bonds between the $\mathrm{Cd}^{2+}$ cation and the cryptand $(2,2,2)$ are loosened; this fact could be also responsible for the decrease of the electroreduction rate.

A decrease in rate constant is also observed for the reduction of $(2,2,2)$ complexes of alkali metal cations, $\mathrm{Li}^{+}, \mathrm{Na}^{+}, \mathrm{K}^{+}$and $\mathrm{Rb}^{+}$, in $\mathrm{PC}$, but only by one order of magnitude. The reaction rates of the cryptates $\mathrm{M}(2,2,2)^{n+}\left(\mathrm{M}^{n+}=\mathrm{Cs}^{+}[6], \mathrm{Mg}^{2+}\right.$, $\left.\mathrm{Ba}^{2+}[7]\right)$ in PC solutions are comparable to those of the corresponding uncomplexed cations. Such behaviour may be explained in terms of adsorption of the alkaline earth cryptates on the mercury electrode [7].

The kinetic parameters for the $\mathrm{Cd}(2,2,2)^{2+} / \mathrm{Cd}(\mathrm{Hg})$ system show that the standard rate constant increases with increasing ligand concentration $\left(\Delta \log k_{\mathrm{s}} /\right.$ $\Delta \log c_{\mathrm{L}} \simeq 0.5$ ). This follows from the fact that the reaction orders of the cathodic and anodic processes are different, being equal to 0 and +1 , respectively. The values of the cathodic and anodic transfer coefficients are different $(\alpha n=0.82$, $\beta n=0.42$ ). This suggests that the mechanism and the geometry of the energy barrier for the cathodic and anodic processes are different. The low values of $\beta n$ suggest that the anodic process is probably controlled by the transfer of the first electron. Since the cathodic transfer coefficient obtained in $\mathrm{AN}$ for the $\mathrm{Cd}^{2+} / \mathrm{Cd}(\mathrm{Hg})$ system is about three times lower than that for the $\mathrm{Cd}(2,2,2)^{2+} / \mathrm{Cd}(\mathrm{Hg})$ system, it seems that the reduction mechanisms for the two reactants are different.

\section{ACKNOWLEDGEMENT}

One of us (J.S.) thanks the Central Electrochemical Project 01.15 for partial support.

\section{REFERENCES}

1 B. Dietrich, J.M. Lehn and J.P. Sauvage, Tetrahedron Lett., 34 (1969) 2885, 2889.

2 J.M. Lehn, Struct. Bonding, 16 (1973) 1.

3 C. Boudon, F. Peter and M. Gross, J. Electroanal. Chem., 117 (1981) 65.

4 F. Arnaud-Neu, B. Spiess and M.J. Schwing-Weill, J. Am. Chem. Soc., 104 (1982) 5641.

5 F. Peter and M. Gross, J. Electroanal. Chem., 61 (1975) 245.

6 F. Peter, J.P. Gisselbrecht and M. Gross, J. Electroanal. Chem., 86 (1978) 115.

7 J.B. Gisselbrecht, F. Peter and M. Gross, J. Electroanal. Chem., 74 (1976) 315.

8 J.P. Gisselbrecht, F. Peter and M. Gross, J. Electroanal. Chem., 96 (1979) 81.

9 J.P. Gisselbrecht and M. Gross, J. Electroanal. Chem., 75 (1977) 637.

10 B.G. Cox, J. Stroka, I. Schneider and H. Schneider, J. Chem. Soc. Faraday Trans. 1, 85 (1989) 187.

11 J.E.B. Randles, Can. J. Chem., 37 (1959) 238.

12 T. Biegler, E.R. Gonzalez and R. Parsons, Collect. Czech. Chem. Commun., 36 (1971) 414

13 N.A. Izmailov, Dokl. Akad. Nauk SSSR, 149 (1963) 1364.

14 B.G. Cox, C. Guminski and H. Schneider, J. Am. Chem. Soc., 104 (1982) 3789.

15 G. Anderegg, Helv. Chim. Acta, 58 (1975) 1218.

$16 \mathrm{H}$. Schneider and J. Stroka, unpublished data. 